\title{
An exploration study on the relationship between social capital and public librarians' personal characteristics
}

\author{
Zahra Jafarzadeh Kermani $^{\mathbf{a}^{*}}$ and Elham Raoufi ${ }^{\mathrm{b}}$
}

${ }^{a}$ Assistant professor, Department of Knowledge \& Information Science, International University of Imam Reza, Mashhad, Iran ${ }^{b}$ M.S student of Knowledge and Information Science in International University of Imam Reza, Mashhad, Iran

\section{CHRON I C L E}

Article history:

Received January 20, 2014

Accepted 30 August 2014

Available online

August 312014

Social capital

Librarian

Personal characteristics

\section{Introduction}

Social capital plays essential role for development of strong long-term employee commitment (Baker, 2000). Njagi (2012) explained the nature of employee promotion in a firm. He tried to find out on how social capital could influence on employee's promotion. The study indicated that employees are social beings but their social relationships could differ from one employee to another. The study also stated that networking was an important factor of human beings. In their survey, Njagi concluded that there was a high relationship between social capital and employee promotion. Zacharakis and Flora (2005) tried to understand the dynamics between different components of social capital. They also tried to find out whether there was an appropriate balance between social capital and cultural reproduction or not. They concluded that community development projects frequently tend to reproduce existing leadership structures. Svendsen (2013) performed a survey and concluded that there was an extensive collaboration between the branch libraries and other public institutions in a study accomplished in Denmark.

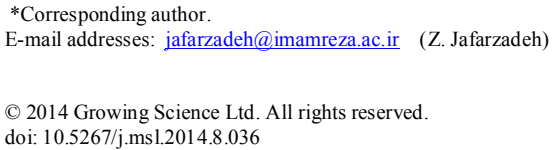


According to Vårheim (2011), public libraries are promising arenas for building social trust, and follow-up investigation looking at the behaviors of many people who participate in different programs for increasing our knowledge on the mechanisms building trust and social capital — that is, for theory development and for library practice.

\section{The proposed study}

This paper presents an empirical investigation to study the relationship between social capital and personal characteristics of the library employees who work at Imam Reza International University in city of Mashhad, Iran. The study uses a questionnaire developed by Nahapiet and Ghoshal (1998) for measuring different components of social capital. The main hypothesis of the survey is associated with an assessment of social capital in this organization. There are five sub-hypotheses in this survey as follows,

1. There is a difference between female and male's social capital.

2. There is a difference between single and marrieds' social capital.

3. There is a difference between employee status and social capital.

4. There is a difference between years of job experiences and social capital.

5. There is a difference between employee's age and social capital.

In our study, we have selected 30 out of 126 employees and distributed the questionnaire to validate the overall questionnaire. Cronbach alpha has been calculated as 0.917 , which is well above the acceptable level. In our survey, there were 126 employees and the proposed study designed a questionnaire, distributed it among all employees and managed to collected 120 properly filled ones. Table 1 demonstrates some basic statistics associated with the social capital components.

Table 1

Mean and standard deviation of relational components of social capital

\begin{tabular}{lcc}
\hline Component & Mean & Standard deviation \\
\hline Trust & 3.03 & 0.851 \\
Common normality & 2.98 & 0.725 \\
Commitment and expectations & 3.08 & 0.825 \\
Identity & 3.78 & 0.772 \\
\hline Total & 3.17 & 0.873 \\
\hline
\end{tabular}

As we can observe from the results of Table 1, identity maintains the highest value and common normality receives the minimum score. In addition, Table 2 demonstrates the summary of different structural components of social capital. As observed in, group relationships maintains the highest value and good organization receives the minimum score.

Table 2

Mean and standard deviation of structural components of social capital

\begin{tabular}{lcc}
\hline Component & Mean & Standard deviation \\
\hline Group relationships & 3.41 & 0.478 \\
Structure of having good group relationships & 3.11 & 0.726 \\
Good organization & 2.85 & 0.758 \\
\hline Total & 3.35 & 0.694 \\
\hline
\end{tabular}


Table 3

Mean and standard deviation of cognitive components of social capital

\begin{tabular}{lcc} 
Component & Mean & Standard deviation \\
\hline Language, rules and common attitude & 3.03 & 0.78 \\
Experiences and common reminders & 3.13 & 0.88 \\
\hline Total & 3.03 & 0.922
\end{tabular}

Table 4

Mean and standard deviation of different components of social capital

\begin{tabular}{lcc}
\hline Component & Mean & Standard deviation \\
\hline Relational capital & 3.17 & 0.873 \\
Structural capital & 3.35 & 0.694 \\
Cognitive capital & 2.30 & 0.922 \\
\hline Total & 3.23 & 0.845 \\
\hline
\end{tabular}

\section{The results}

In this section, we present details of our findings on testing various hypotheses of the survey.

\subsection{The first hypothesis: The relationship between gender and social capital}

The first hypothesis of the survey investigates the relationship between gender and social capital. Table 5 shows mean and standard deviation of participants' gender in terms of various categories of social capital.

\section{Table 5}

The summary of mean and standard deviation of gender in terms of social capital and gender

\begin{tabular}{lclcccc}
\hline Variable & \multicolumn{2}{c}{ Male } & \multicolumn{2}{c}{ Female } & \multicolumn{2}{c}{ Total } \\
\cline { 2 - 7 } & Mean & Std. dev. & Mean & Std. dev. & Mean & Std. dev. \\
\hline Relational & 3.17 & 0.861 & 3.00 & 0.855 & 3.35 & 0.873 \\
Structural & 3.35 & 0.659 & 3.22 & 0.71 & 3.49 & 0.694 \\
Cognitive & 3.30 & 0.826 & 3.14 & 0.826 & 3.47 & 0.922 \\
\hline Total & 3.23 & 0.842 & 3.03 & 0.802 & 3.44 & 0.845 \\
\hline
\end{tabular}

According to the results of Table 5, most components maintain an average of well above 3 . In addition, female maintain bigger numbers than men and finally, the mean of structural capital is greater than other two components of social capital. Table 6 shows details of the results of Levin and t-student tests for the first hypothesis of the survey.

\section{Table 6}

The summary of t-student and Levin tests

\begin{tabular}{lccccc}
\hline & \multicolumn{3}{c}{ Levin test } & \multicolumn{3}{c}{ t-student test } \\
\cline { 2 - 5 } & Value & P-Value & t-value & df & P-value \\
\hline$\sigma_{1}{ }^{2}=\sigma_{2}{ }^{2}$ & 1.262 & 0.262 & -3.064 & 118 & 0.003 \\
$\sigma_{1}{ }^{2} \neq \sigma_{2}{ }^{2}$ & & & -3.072 & 117.76 & 0.003 \\
\hline
\end{tabular}

According to the results of Table 6 , since t-student value is statically significant, we may, therefore, reject the null hypothesis and conclude that there is a meaningful difference between social capital in terms of gender. 


\subsection{The second hypothesis: The relationship between marital status and social capital}

The second hypothesis of the survey studies the relationship between marital status and social capital. Table 6 demonstrates mean and standard deviation of participants' marital status in terms of different categories of social capital. Again, according to the results of Table 7, most components maintain an average of well above 3 . In addition, married employees maintain bigger numbers than singles and finally, the mean of structural capital is greater than other two components of social capital. Table 8 presents details of the results of Levin and t-student tests for the second hypothesis of the survey.

Table 7

The summary of mean and standard deviation of social capital and marital status

\begin{tabular}{lcccccc}
\hline Variable & \multicolumn{2}{c}{ Single } & \multicolumn{2}{c}{ Married } & \multicolumn{2}{c}{ Total } \\
\cline { 2 - 7 } & Mean & Std. dev. & Mean & Std. dev. & Mean & Std. dev. \\
\hline Relational & 3.24 & 0.869 & 3.17 & 0.863 & 2.87 & 0.873 \\
Structural & 3.38 & 0.600 & 3.35 & 0.714 & 3.22 & 0.694 \\
Cognitive & 3.34 & 0.965 & 3.30 & 0.877 & 3.13 & 0.922 \\
\hline Total & 3.29 & 0.825 & 3.23 & 0.841 & 2.96 & 0.845 \\
\hline
\end{tabular}

Table 8

The summary of t-student and Levin tests

\begin{tabular}{lccccc}
\hline & \multicolumn{3}{c}{ Levin test } & \multicolumn{3}{c}{ t-student test } \\
\cline { 2 - 6 } & Value & P-Value & t-value & df & P-value \\
\hline$\sigma_{1}{ }^{2}=\sigma_{2}{ }^{2}$ & 0.065 & 0.304 & -1.659 & 118 & 0.1 \\
$\sigma_{1}{ }^{2} \neq \sigma_{2}{ }^{2}$ & & & -1.589 & 31.69 & 0.122 \\
\hline
\end{tabular}

According to the results of Table 8, since t-student value is not statically significant, therefore, we cannot reject the null hypothesis and conclude that there is not any meaningful difference between social capital in terms of marital status.

\subsection{The third hypothesis: The relationship between employment status and social capital}

The third hypothesis of the survey studies the relationship between employment status and social capital. Table 9 demonstrates mean and standard deviation of participants' employment status in terms of various categories of social capital.

Table 9

The summary of mean and standard deviation of social capital and employment status

\begin{tabular}{|c|c|c|c|c|c|c|c|c|c|c|}
\hline \multirow[t]{2}{*}{ Variable } & \multicolumn{2}{|c|}{ Regular } & \multicolumn{2}{|c|}{ Contractor } & \multicolumn{2}{|c|}{ Agreement } & \multicolumn{2}{|c|}{ Contract react } & \multicolumn{2}{|c|}{ Other firms } \\
\hline & Mean & Std. dev. & Mean & Std. dev. & Mean & Std. dev. & Mean & Std. dev & Mean & Std. dev. \\
\hline Relational & 3.16 & 0.842 & 3.53 & 0.943 & 3.11 & 0.601 & 3.07 & 0.958 & 3.00 & 0.866 \\
\hline Structural & 3.24 & 0.657 & 3.71 & 0.588 & 3.44 & 0.726 & 3.41 & 0.747 & 3.18 & 0.728 \\
\hline Cognitive & 3.14 & 0.833 & 3.88 & 0.781 & 3.22 & 0.833 & 3.30 & 0.712 & 3.24 & 0.903 \\
\hline Total & 3.16 & 0.766 & 3.65 & 0.862 & 3.11 & 0.782 & 3.26 & 0.859 & 3.00 & 0.984 \\
\hline
\end{tabular}

One more time, based on the results of Table 9, most components have an average of well above 3 . In addition, structural capital maintains higher mean than the other two components of social capital. Table 10 presents details of the results of ANOVA test for the third hypothesis of the survey.

Table 10

The summary of ANOVA for testing the effect of employment type

\begin{tabular}{lccc}
\hline Group & Sum of Squares & Degree of freedom & Mean of Squares \\
\hline Between group & 1611.55 & 4 & 402.887 \\
Inside group & 23574.817 & 115 & 204.998 \\
\hline & & 119 & \\
\hline
\end{tabular}


According to the results of Table 10 , since F-value is not statically significant, therefore, we cannot reject the null hypothesis and conclude that there was not any meaningful difference between social capital for various types of employment.

\subsection{The fourth hypothesis: The relationship between job experience and social capital}

The fourth hypothesis of the survey studies the relationship between employments' job experiences and social capital. Table 11 shows mean and standard deviation of participants' job experiences in terms of various categories of social capital.

\section{Table 11}

The summary of mean and standard deviation of social capital and job experience

\begin{tabular}{lcccccccccc}
\hline Variable & \multicolumn{3}{c}{$<5$} & \multicolumn{4}{c}{$5-10$} & \multicolumn{2}{c}{$11-15$} & \multicolumn{2}{c}{$16-20$} & $>20$ \\
& Mean & Std. dev. & Mean & Std. dev. & Mean & Std. dev. & Mean & Std. dev. & Mean & Std. dev. \\
\hline Relational & 3.00 & 0.953 & 3.03 & 0.964 & 3.46 & 0.65 & 3.16 & 0.834 & 2.91 & 0.988 \\
Structural & 3.22 & 0.600 & 3.37 & 0.809 & 3.49 & 0.559 & 3.37 & 0.761 & 3.09 & 0.831 \\
Cognitive & 3.35 & 0.885 & 3.27 & 0.861 & 3.54 & 0.90 & 3.16 & 0.688 & 2.73 & 0.786 \\
\hline Total & 3.13 & 0.815 & 3.10 & 0.821 & 3.49 & 0.651 & 3.21 & 0.713 & 2.91 & 0.944 \\
\hline
\end{tabular}

Again, based on the results of Table 11, most components have an average of well above 3 . In addition, structural capital maintains higher mean than the other two components of social capital. Table 12 shows details of the results of ANOVA test for the fourth hypothesis of the survey.

\section{Table 12}

The summary of Chi-Square for testing the effect of job experience

\begin{tabular}{lccc}
\hline Group & Sum of Squares & Degree of freedom & Mean of Squares \\
\hline Between group & 173.177 & 4 & 444.793 \\
Inside group & 23407.367 & 115 & 203.541 \\
\hline & & 119 & \\
\hline F-value $=2.185$ Sig. $=0.075$ & & &
\end{tabular}

According to the results of Table 12, since F-value is not statically significant, therefore, we cannot reject the null hypothesis and conclude that there was not any meaningful difference between social capital for people with various job experiences.

\subsection{The fifth hypothesis: The relationship between age and social capital}

The fifth hypothesis of the survey studies the relationship between employments' age and social capital. Table 13 demonstrates mean and standard deviation of participants' age in terms of various categories of social capital. Table 14 shows details of the results of ANOVA test for the last hypothesis of the survey.

Table 13

The summary of mean and standard deviation of social capital and participants' age

\begin{tabular}{lcccccccc}
\hline Variable & & $20-30$ & \multicolumn{2}{c}{$31-40$} & \multicolumn{3}{c}{$41-50$} & \multicolumn{2}{c}{$51-60$} \\
\hline & Mean & Std. dev. & Mean & Std. dev. & Mean & Std. dev. & Mean & Std. dev. \\
\hline Relational & 3.09 & 0.928 & 3.28 & 0.833 & 2.96 & 0.935 & 3.25 & 0.50 \\
Structural & 3.38 & 0.751 & 3.38 & 0.644 & 3.32 & 0.802 & 3.00 & 0.001 \\
Cognitive & 3.41 & 0.912 & 3.43 & 0.901 & 2.88 & 0.833 & 3.20 & 0.156 \\
\hline Total & 3.16 & 0.92 & 3.33 & 0.825 & 3.04 & 0.841 & 3.25 & 0.50 \\
\hline
\end{tabular}

Table 14

The summary of ANOVA for testing the effect of participants' age

\begin{tabular}{lccc}
\hline Group & Sum of Squares & Degree of freedom & Mean of Squares \\
\hline Between group & 757.658 & 4 & 189.414 \\
Inside group & 24428.709 & 115 & 212.424 \\
\hline & 25186.367 & 119 & \\
\hline
\end{tabular}

F-value $=0.892$ Sig. $=0.471$ 
According to the results of Table 14, since F-value is not statically significant, therefore, we cannot reject the null hypothesis and conclude that there was not any meaningful difference between social capital for people with various age.

\section{Conclusion}

In this paper, we have presented an empirical investigation to study the effects of some librarians' personal characteristics on social capital. The study has applied a standard questionnaire in Likert scale, distributed among all population of the survey and using some statistical tests, it has concluded that although age, job experience, marital status and type of employment had no impact on social capital, gender played essential role on this survey. In other words, our survey has indicated that women presented more social capital than men did.

\section{Acknowledgement}

The authors would like to thank the anonymous referees for constructive comments on earlier version of this paper.

\section{References}

Baker, W. E. (2000). Achieving success through social capital: Tapping the hidden resources in your personal and business networks (pp. 110-115). San Francisco: Jossey-Bass.

Njagi, L. K. (2012). Relationship between social capital and employee promotion. International Journal of Business \& Commerce, 1(10), 1-13.

Nahapiet, J., \& Ghoshal, S. (1998). Social capital, intellectual capital, and the organizational advantage. Academy of Management Review, 23(2), 242-266.

Svendsen, G. L. H. (2013). Public libraries as breeding grounds for bonding, Bridging and institutional social capital: The case of branch libraries in rural Denmark. Sociologia Ruralis, 53(1), 52-73.

Vårheim, A. (2011). Gracious space: Library programming strategies towards immigrants as tools in the creation of social capital. Library \& Information Science Research, 33(1), 12-18.

Zacharakis, J., \& Flora, J. (2005). Riverside: A case study of social capital and cultural reproduction and their relationship to leadership development. Adult Education Quarterly, 55(4), 288-307. 